\title{
INFLUÊNCIAS DAS NOVAS TECNOLOGIAS PARA DESIGNERS E MAKERS
}

\author{
Taís Silva Lima \\ Universidade Federal de Minas Gerais - UFMG \\ ts.silva.lima@gmail.com \\ Glaucinei Rodrigues Corrêa \\ Universidade Federal de Minas Gerais - UFMG \\ glaucinei.correa@gmail.com
}

Resumo: Este artigo aborda as influências da Terceira Revolução Industrial no design e na comunidade maker, como forma de incitar a reflexão e discussão das mudanças derivadas das novas tecnologias de fabricação. 0 ponto de partida deste estudo está nos apontamentos dos diferentes aspectos tecnológicos e sociais da história industrial. Por meio do barateamento de alguns maquinários de pequeno porte que produzem industrialmente em baixa escala, avalia-se o gradativo empoderamento da comunidade maker, da população adepta ao do-it-yourself e dos designers que se dedicam a projetar e produzir bens materiais. Além disso, é possível notar a formação de um consumidor mais participativo e consciente, que se informa e expressa por meio das diversas redes colaborativas. Assim, conclui-se sobre a necessidade de participação efetiva dos designers nas discussões, mudanças e definições derivadas desse meio.

Palavras-chave: Terceira Revolução Industrial, Design, Maker, Do-lt Yourself

\begin{abstract}
This paper discusses current issues and future influences of the Third Industrial Revolution in design and maker community as a way to encourage reflection and discussion of possible changes derived from new fabrication technologies. The starting point of this study are the notes of different technological and social aspects of industrial history. Through the cheapness of small machinery that produce industrially on a small scale, the gradual empowerment of the maker community, population adept do-ityourself and designers dedicated to designing and producing material goods. Furthermore, it is possible to note the formation of a more participatory and informed consumers, which informs and expressed through various collaborative networks. Therefore, concludes on the need for effective participation of designers in the discussions, changes and definitions derived from this environment.
\end{abstract}

Keywords: Third Industrial Revolution, Design, Maker, Do-It-Yourself 


\section{INTRODUÇÃO}

Para compreender as relações envolvidas na produção industrial contemporânea é necessário fazer a conexão dos três seguintes temas: Terceira Revolução Industrial, Do-It-Yourself e Design.

Em relação à Terceira Revolução Industrial pode-se considerar a abrangência de modificações que as inovações de técnicas produtivas podem causar no eixo projeto-indústria-consumidor. O Do-It-Yourself $(D / Y)$, traduzido literalmente para o português como Faça Você Mesmo, é apontado como um fenômeno social relacionado com a apropriação e modificação de bens industriais pelo consumidor que não tem conhecimento profissional com a atividade (também referido neste trabalho como DlYers, Makers e Fazedores) para construir, transformar ou consertar algum produto.

Em relação ao design, Cardoso (2008) destaca que o design é fruto de três momentos históricos: 1) industrialização: reorganização da fabricação e distribuição de bens para abranger um leque cada vez maior e mais diversificado de produtos e consumidores. 2) urbanização moderna: ampliação e adequação das concentrações de população em grandes metrópoles e 3) globalização: interação de redes de comércio, transportes e comunicação, assim como todo o sistema financeiro e jurídico que as regulam.

O ponto de partida para justificar o tema tratado, ou seja, as novas tecnologias, é o aumento significativo das discussões e publicações quanto à criação e inserção de novos maquinários pertencentes ao que alguns pesquisadores e entusiastas denominam de Terceira Revolução Industrial.

Esse contexto contemporâneo possibilita refletir sobre as condições propiciadas pela Terceira Revolução Industrial, por meio de maquinários, pelo acesso às informações através de redes globais de comunicação, bem como sobre o crescimento da autonomia em aprender, participar, projetar e produzir produtos.

É possível notar que algumas empresas já respondem em maior ou menor grau a essa forma de produção participativa, envolvendo o consumidor no projeto, transporte ou até montagem do produto. Segundo Mintel (2003; 2005) apud Watson e Shove (2005): "O DIY representa um crescimento constante e substancial enquanto fenômeno cultural no Reino Unido, [...]. Por volta de $62 \%$ da população adulta afirmam realizar DIY, sendo que $13 \%$ do tempo nas atividades domésticas são DIY em 2000."

Entretanto, conforme afirmam Watson e Shove (2005) há ainda muitas lacunas a serem preenchidas, as quais abrem campo para sugerir elos de estudos entre o design, o DIY e a Terceira Revolução Industrial. Segundo esses autores a quase invisibilidade do termo DIY em fontes bibliográficas refletem não apenas especificidades linguísticas, mas um campo mais amplo negligenciado pelas ciências sociais, apesar de sua escala enquanto um fenômeno social.

Os resultados apresentados neste trabalho foram obtidos por pesquisas bibliográficas, referentes ao contexto dos Estados Unidos da América e Europa em sua maioria, por se tratar de um tema contemporâneo que ainda conta com implementação recente.

\section{INOVAÇÕES TECNOLÓGICAS DA INDUSTRIALIZAÇÃO E DO PROCESSO PRODUTIVO}

O processo produtivo decorrente da atividade artesanal dependia de trabalhadores altamente qualificados que usavam ferramentas simples, mas flexíveis, para fazer exatamente o que o consumidor pedia - um item de cada vez. O domínio de 
todo o processo produtivo pelo artesão, assim como o conhecimento do usuário refletia na produção (WIKSTRÖM, 1996). Esse tipo de produção persiste até os dias atuais em alguns nichos de produção exclusiva, porém com custo muito alto para a grande maioria das pessoas (WOKMACK; JONES; ROSS, 2007).

As mudanças tecnológicas que se iniciaram na Primeira Revolução Industrial incluíam o uso de novos materiais como o ferro, o uso de novas fontes energéticas, como o carvão e a eletricidade e, por fim, o invento de novas máquinas que aumentavam a produção em série com menor uso da força humana. Além disso, o avanço tecnológico permitiu a padronização do processamento da matéria prima, o aumento da escala produtiva, a fabricação de produtos novos, mais competitivos pela sua qualidade e baixo custo (CARDOSO, 2008). Não há um consenso de quando esta etapa se iniciou e quais inovações a constituíram, mas alguns progressos relacionados à Segunda Revolução Industrial incluíam o desenvolvimento de meios de transporte e comunicação. Seguiu-se a produção em massa de bens de consumo e técnicas variadas de preservação alimentar. Os profissionais semi-qualificados ou desqualificados utilizavam máquinas muito caras com propósito único e seus produtos eram padronizados, rígidos a modificações e produzidos em grandes volumes. Para isso eram necessários suprimentos, trabalhadores e espaços extras. Entender o comportamento do consumidor passou a ser elemento de interesse para o mercado cada vez mais competitivo da indústria. As principais características do comprador, apontadas por Kotler (1994), são os fatores culturais (classe social e cultural), sociais (família, grupo de referência, posição social) e psicológicos (motivação, percepção, aprendizagem, crenças e atitudes). Dessa forma, acionado pelo estímulo de marketing (preço, produto) e outros de ordem econômica, tecnológica, política e social, o consumidor processa informações e toma decisões.

Segundo resultado apontado por Wokmack; Jones; Ross (2007) o consumidor recebe redução de preço, mas à custa da variedade e por meio de métodos de trabalho que a maioria dos funcionários acha chato e desanimador. $O$ aumento da divisão do trabalho, inclusive com a separação entre o projeto e a execução, limitou o conhecimento de toda a atividade fabril, tornando o trabalhador um especialista técnico, executando atividades restritas dentro de todo o processo produtivo. Ocorreu o aumento da velocidade de produção e a simplificação das habilidades e conhecimentos necessários por parte do trabalhador (WIKSTRÖM, 1996).

A partir das décadas de 80 e 90, percebe-se que, além das implicações derivadas da mudança tecnológica, existe certa redução no interesse em produzir manualmente. Primeiro, os empregos industriais já não eram maneiras seguras de ingressar e de continuar na classe média e a oficina perdeu até seu apelo vocacional. Como substitutos entram em cena os teclados e telas. Os computadores eram os novos protagonistas indispensáveis nos bons empregos (ANDERSON, 2012). Durante a Revolução Industrial, o imenso esforço para produzir bens físicos foi a base principal do poder da hierarquia corporativa no controle do capital humano e outros bens intangíveis. Com a redução do custo inicial em investimentos de capital necessários para a produção independente e para entrar no mercado, ocorreu a mesma descentralização que o desktop provocou. Segundo Carson (2010). O aumento do valor do capital humano e o poder de hierarquias corporativas tornaram-se menos relevantes, foi possível que trabalhadores se tornassem empreendedores, começando novas empresas sob seu próprio controle. Segundo Carson (2010) a diferença entre o 
que pode ser feito em casa e que pode ser realizado em um ambiente de trabalho tem diminuído nos últimos dez a quinze anos.

\subsection{Tecnologias da terceira revolução industrial}

O ambiente fabril é ícone da Primeira e Segunda Revolução Industrial. As máquinas, ferramentas, linhas de produção e economias de escala fazem parte do ideal de configuração industrial sendo quase inconcebível dissociá-las. A reformulação das indústrias possibilita a eliminação parcial da linha de montagem, da cadeia produtiva e até mesmo das ferramentas, tornando possível o desenvolvimento e fabricação de produtos por meio do aperfeiçoamento contínuo das redes de comunicação e tecnologias produtivas. Conforme Koff; Gustafson (2012), pesquisas relacionadas à Terceira Revolução Industrial orientam a criação de novos produtos, com propriedades estruturais e materiais totalmente novos. Dentre os desenvolvimentos tecnológicos é possível se destacar alguns equipamentos de maior representatividade, como as máquinas de Controle Numérico Computadorizado (CNC), o corte a laser, o scanner 3D e a impressora 3D.

De forma geral, essas máquinas possibilitam grande variedade de materiais a serem trabalhados, com grande variabilidade dimensional das máquinas e exatidão do que é produzido (ANDERSON, 2012). A prototipagem e produção está gradativamente mais barata para o consumidor, seu manuseio está mais fácil, novos materiais e técnicas estão possibilitando novos usos, e a internet está unindo tudo isso, possibilitando que parte do processo possa ser feito em casa, no escritório, em um hospital ou na escola, trazendo a fabricação para fora das indústrias, assim como os $P C$ s trouxeram a computação para ambientes não tradicionais.

A evolução das tecnologias de fabricação não está apenas se ampliando para variadas áreas, mas também gerando transformações diversas com a mudança dos materiais utilizados e com o aumento da complexidade dos objetos produzidos.

Mesmo confiantes dos seus efeitos, autores como Slick (2014) e McCutcheon (2014) lembram que a tecnologia está em evolução com muitos limites e desafios. Eles apontam questões referentes ao alto custo, baixa velocidade (condicionada à qualidade no acabamento), limitação de matéria prima, usabilidade e propriedade intelectual como fatores de limitação à popularização. Vale lembrar o apontamento de Slick (2014), sobre implicações morais já existentes, e outras que ainda surgirão, como a produção de armas e o bioprinting pelas impressoras 3D.

\subsection{Contexto histórico do DIY}

O crescente nível de consumismo, segundo Wolf \& Mc Quitty (2011), mantém nossos corpos e mentes ociosos, e degradam nossa capacidade de criar e inovar. 0 problema tende a piorar com as compras on-line, que eliminam a necessidade até mesmo de sair de casa. Os autores apontam como vantajosa e saudável o retorno às atividades práticas e criações de produtos em casa, onde podemos nos divertir, aprender novas tarefas e ter mais contato com o mundo que nos cerca.

Segundo reflexões de Gelber (1997), as famílias "Vitorianas" da classe média exaltavam o fato de não "levantarem um dedo" para promover a manutenção doméstica. Nesse contexto cabia à mulher gerir o ambiente doméstico, exercendo apenas atividades manuais como lazer, produção de itens pessoais ou decoração domiciliar. Havia uma grande relutância feminina em usar ferramentas consideradas 
masculinas, referidas pelo autor segundo a regra do "meio quilo", em que as ferramentas que ultrapassassem esse peso eram para o uso dos homens. A obrigação familiar masculina se restringia ao sustento familiar, sendo o homem uma figura pouco participativa no ambiente doméstico, não havendo expectativa nem desejo de se envolver nas atividades domésticas. Por exercer maior proximidade nas tarefas artesanais, acredita-se que as mulheres seriam potencialmente as grandes precursoras do movimento Maker, já que os homens teriam perdido sua tradição manual com o afastamento do trabalho agrícola e artesanal ao trabalhar na indústria (GELBER, 1997). Considera-se que um dos primeiros momentos de mudança reflexiva quanto às atribuições e responsabilidades voltadas a cada gênero ocorreu com a entrada das mulheres no mercado de trabalho. Ao exercer atividades fora do lar houve uma complicação da rotina doméstica, que contribuiu na reflexão dos papéis sociais.

Paralelamente, a sociedade se questionava quanto ao reflexo da industrialização. O movimento Arts \& Crafts, por exemplo, na segunda metade do século XIX defendia o artesanato em contraposição à produção mecanizada e em massa. Pregava-se a inclusão da produção artística e artesanal, em que houvesse um envolvimento na produção. Em reportagem de 1910 intitulada "Recreation with tools", falava-se que toda pessoa precisava de algum interesse além da rotina de trabalho, para manter uma postura de equilíbrio essencial para uma boa vida. Com o início da I Guerra Mundial, historiadores, como T.J. Jackson Lears, argumentam que o movimento Arts \& Crafts se reduziu a um hobby em que o trabalhador revigorava suas energias para voltar ao trabalho após um fim de semana em atividades DIY (GELBER, 1997).

O jornalista Julian Starr elogiou o trabalho não profissional com madeira pelos seus benefícios psicológicos e criativos para contrapor o tédio do trabalho repetitivo. Atkinson (2006) reflete quanto à transposição do estigma social do trabalho manual que agora não se relaciona apenas a uma necessidade, mas a um engajamento prazeroso, diferente do que fora percebido pelas classes trabalhadoras Vitorianas e Edwardianas.

A família moderna do século XX mudou com a participação masculina em manutenções domésticas intituladas "hard", antes de responsabilidade de algum profissional. Assim, eles mantêm sua função distinta, com a criação de um espaço doméstico de domínio masculino. O homem começa a se responsabilizar por parte das atividades domésticas, participa da criação dos filhos e tem a mulher como companheira de atividades de lazer. Um outro reflexo do movimento Arts \& Crafts foi a implantação de cursos em habilidades manuais em escolas públicas (GELBER, 1997). Podemos perceber o fortalecimento desse mercado com a primeira furadeira portátil em 1914 pela Black \& Decker. Apesar do seu fracasso de venda inicial, em 1946 ocorre o relançamento, com uma versão menor e mais barata, e vende-se em torno de 15 milhões de furadeiras $B \& D$ e de outras fábricas nesse período (GELBER, 1997).

É importante também compreender a relação do DIY quando atrelado às restrições dos períodos de guerra. Segundo Gelber (1997) a falta de dinheiro estava entre os principais desafios da I Guerra; enquanto que na II Guerra Mundial era a falta de profissionais qualificados para os trabalhos domésticos, pois a guerra os absorvia. Isso contribuiu na mudança expressiva do paradigma do trabalho doméstico "hard" feito por mulheres. Por terem ocupado as posições masculinas em casa e no trabalho, em 1941 algumas entidades organizaram cursos educativos para mulheres na 
manutenção de eletrodomésticos. Frases como "Every woman her own handyman!" e outras campanhas incentivavam o novo papel da mulher na sociedade (Figura 1).
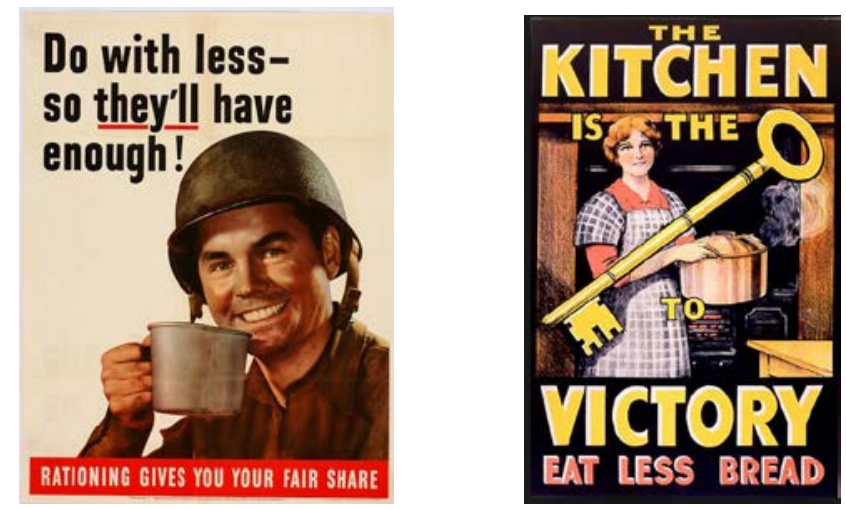

Figura 1 - Propagandas durante o período de guerra que incentivavam a redução do consumo.

Fonte: Imagem da esquerda, acesso em 5/11/2013:

<http://content.libraries.wsu.edu/cdm/ref/collection/propaganda/id/209>

Imagem da direita, acesso em 15/10/2013:

<http://www.iwmprints.org.uk/image/727060/the-kitchen-is-the-key-to-victory>

Durante e após a II Guerra Mundial a publicação de livros por W. P. Matthew e programas da rádio BBC confirmavam a preocupação com a preservação de recursos. Assim, campanhas como "Mrs Sew and Sew", "Dig for Victory" e "Make do and Mend" estimulavam as pessoas a reformarem suas roupas ou a plantarem verduras em seus quintais. Além de uma necessidade financeira, essas eram atitudes esperadas e respeitadas socialmente (ATKINSON, 2006).

Com o fim da II Guerra Mundial permanece a escassez por trabalhadores profissionais e incentivos para a continuidade das atividades de automanutenção doméstica. Como abordado no livro de "Why not help others" (1946), quanto menos trabalhadores fossem chamados para atividades corriqueiras, haveria maior disponibilidade de profissionais para a reconstrução do país (GELBER, 1997).

A relação formada entre indústria e consumidor trouxe benefícios às estratégias adotadas pelo mercado produtivo. Com novas tecnologias e um consumidor mais qualificado, tendências de Do-lt-Yourself continuaram a se difundir, principalmente na Europa e nos Estados Unidos, valorizando o design, o marketing e a produção, além do consumo e do descarte. O DIY ultrapassa a condição de necessidade pela falta de recursos e profissionais qualificados no mercado, para se firmar enquanto um fenômeno social (WATSON; SHOVE, 2005).

\subsection{O movimento maker}

As inovações tecnológicas disponíveis majoritariamente em países do hemisfério norte, possibilitam reconfigurar o modelo produtivo industrial e propicia uma nova forma de se pensar o Faça-Você-Mesmo. A facilidade de comunicação e o acesso a informações pela Web ajudam a configurar o novo movimento Maker.

"Depois de se iniciar como necessidade e se firmar como atividade de criação/lazer", agora diante dos avanços das novas tecnologias como a impressora 3D, Koff; Gustafson (2012) clamam que a produção DIY voltará à tona, pois teremos oportunidade de fazer bem em pequena escala. $O$ autor destaca que a associação de tecnologia 3D e DIY transforma indivíduos, pequenas empresas e departamentos 
corporativos em "fazedores". Para Anderson (2012) os Makers se diferenciam, pois, além de projetarem em seus computadores e produzirem em máquinas de fabricação pessoais, compartilham instintivamente suas criações on-line, conjugando esforços para construir coisas em escala nunca vista em termos DIY.

Mais do que provocar debate no campo das ciências sociais, as novas condições tecnológicas propiciam o domínio da criação até a execução. Desta forma, o DIY ganha relevância também no cenário econômico de pequena escala. Conforme afirma Koff; Gustafson (2012), as pessoas têm agora a oportunidade, em pequena escala, até mesmo como um hobby, para fazê-lo sozinho, e fazê-lo muito bem. "

\subsection{Democratização, acesso por redes colaborativas e financiamentos coletivos}

As tecnologias digitais ocupam um papel central nas profundas mudanças experimentadas em todos os aspectos da sociedade. Entre as mudanças mais significativas da internet está a possibilidade de expressão e sociabilização através de ferramentas de comunicação, construção e interação, mediadas pelo computador cuja popularização tem crescido de forma constante no mundo inteiro (RECUERO, 2009).

A constituição de redes na Web permite que o maker compartilhe seus projetos para serem usados livremente por outros, com a criação de um ambiente open-source (código aberto) onde milhares de makers criam as mais diversas coisas, nas mais diversas áreas, utilizando as novas tecnologias de fabricação para que esses projetos fiquem cada vez mais replicáveis e acessíveis (LEMOS, 2013).

Por meio dos valores que assegurem o acesso comunitário como fonte de prosperidade, bem estar e resiliência a plataforma Shareable se fortalece pela comunidade que colabora e compartilha suas diversas inspirações como forma de alcançar a produção e consumo descentralizado. O Shareable, assim como o movimento Maker mostram um caminho baseado no compartilhamento. Um projeto ícone é o Arduino (uma plataforma aberta de prototipação eletrônica, composta por hardware-placa controladora, e software - ambiente de desenvolvimento). Seus principais usuários são em grande parte amadores, artistas e designers atraídos pelo baixo custo, simplicidade e flexibilidade. A forma como cada Maker irá usar o Arduino depende muito mais da sua criatividade do que de limitações técnicas ou de conhecimento em eletrônica. Mais do que isso, o movimento maker conta com uma grande comunidade empenhada em ajudar novos usuários.

No Brasil, o blog Fazedores (LEMOS, 2013) foi criado em dezembro de 2013 para fomentar o Movimento Maker no país. Seu autor criou um ponto de encontro e compartilhamento de ideias e conhecimentos em diversos ramos da cultura maker.

A dimensão do movimento Maker tem obtido credibilidade enquanto possibilidade de negócio através do crowdfunding, ou seja, "financiamento coletivo", caracterizado pelo fato de se tratar de um esforço coletivo para financiar ou viabilizar uma ideia ou projeto. Ou seja, enquanto em um financiamento tradicional poucos agentes contribuem com grandes quantias, no crowdfunding, a comunidade contribui com pequenas quantias para que o montante total seja levantado, e receba recompensas, brindes ou mercadorias investidas (LEMOS, 2013). O conceito do financiamento coletivo pode ser utilizado para as mais diversas causas, dependendo do projeto a ser financiado e da plataforma que operacionaliza a transação. Kickstarter é hoje a maior plataforma de crowdfunding do mundo, mas podemos citar também a Catarse, Kicante, Benfeitoria entre outras que têm se despontado nacionalmente. 
Além de ser uma alternativa interessante para o financiamento de projetos, uma campanha de crowdfunding bem feita funciona, segundo Anderson (2012) e Lemos (2013), como uma excelente pesquisa de mercado e pode dizer muito sobre o futuro sucesso comercial do projeto. Assim, se o projeto não obter financiamento, isto pode ser um indicador que talvez não exista demanda para aquela ideia e que ela deva ser modificada ou cancelada. Isto tudo faz do crowdfunding uma alternativa para que makers tenham uma pesquisa de mercado simples, de maneira eficaz e econômica, que culmina no financiamento através da pré-venda do produto para seu público alvo.

Mesmo com um modelo interessante, essas plataformas não estão livres de problemas e polêmicas. Uma questão é a dificuldade em atender as demandas criadas após o financiamento, pois uma coisa é projetar um produto em seu computador e montar um protótipo em sua oficina, outra, bem diferente, é produzir e entregar milhares de unidades para clientes no mundo todo.

\section{A INFLUÊNCIA DA TERCEIRA REVOLUÇÃO INDUSTRIAL NO DESIGN}

$O$ acesso às novas tecnologias tem a capacidade de mudar aspectos que vão desde o projeto até a produção. Além do avanço quanto ao uso de novos materiais e equipamentos, a Terceira Revolução Industrial pode influenciar diretamente na atividade exercida durante o processo de desenvolvimento de projetos.

A prototipagem rápida é um grupo de técnicas para fabricar partes ou modelos de objetos de maneira ágil para obter conjuntos ou peças em quantidades e condições que não são possíveis na linha de produção normal. Na maior parte das vezes, a prototipagem rápida é usada para construir modelos de estudo, análise e simulações para testar peças e montagens, antes de colocá-las na linha de produção ou para refinar um novo produto, perceber e corrigir falhas de forma mais barata e eficaz (LEMOS, 2013). Ao associar esse avanço tecnológico às etapas de pesquisa, criação, produção e distribuição de um produto podemos descrever as seguintes mudanças:

Na criação: modelagem e visualização 3D desempenham um papel crucial nas fases iniciais de desenvolvimento do produto. No passado, os softwares eram muitas vezes caros, tornando impraticável o uso pessoal. Hoje, segundo Koff; Gustafson (2012), alguns programas simplificaram a modelagem, uma vez que a maioria dos PCs domésticos pode executar alguns dos softwares especializados, tais como Creo 2.0 ou SolidWorks. Além do mais, há uma série de ferramentas de modelagem gratuitas ou de baixo custo, que exigem um conhecimento simplificado, tais como 3DTin, SketchUp, Blender e o Tinkercad. Uma gama de scanners 3D acessíveis permite que objetos físicos sejam digitalizados, modificados (dentro de limites) e reproduzidos diretamente por uma impressora 3D reduzindo ou eliminando a necessidade de se modelar, permitindo a popularização progressiva de se gerar modelos sofisticados (KOFF; GUSTAFSON, 2012). O processo de criação também pode ganhar a participação do consumidor, como no caso do software 3D Digital Forming, que permite às empresas compartilharem seus produtos com seus clientes para que sejam personalizados.

$\mathrm{Na}$ produção: à medida que mais organizações e indivíduos se tornam "fabricadores", a linha que separa fabricante e cliente enfraquece. Se há uma loja no meio, ela também enfraquece. Se a produção passa para a revenda e consumidores passam para a produção, a produção tradicional pode ser diferente no futuro. Entre as tendências emergentes, decorrentes das novas tecnologias no design e na produção, Koff; Gustafson (2012) destacam a redução dos estoques pela possibilidade de serem 
produzidos próximos da área de consumo, de forma que os produtos não fiquem muito tempo nas prateleiras. A produção de características mais competitivas, projetos abertos (produção colaborativa) e personalizados serão bem mais comuns. A economia por preços vantajosos e produção em massa será desafiada pela fabricação just-in-time, perto do ponto de venda.

Na Distribuição: no passado, se o financiamento era escasso, o designer autônomo, inicialmente fabricava e comercializava um baixo volume de produtos para uma aplicação especializada. Ao longo do tempo, se o produto fosse um sucesso, mais investimentos eram feitos até que volumes maiores pudessem ser comercializados, atendendo a uma base de clientes mais ampla. Agora, segundo Koff; Gustafson (2012), graças a empresas que atendem a mercados on-line, como Thingiverse, Shapeways e Sculpteo, o problema de marketing e distribuição foi significativamente reduzido. Algumas delas pagam aos designers por seus produtos além de lidar com a aquisição e distribuição dos produtos em qualquer lugar do mundo.

\subsection{O papel do designer}

Novas técnicas produtivas demandam novas habilidades e conhecimentos, como também podem estabelecer contato entre áreas de conhecimento até então afastadas ou desvinculadas. A questão da possível mudança dos papéis exercidos no mercado de trabalho em decorrência da Terceira Revolução Industrial tem instigado debates. Um deles, promovido por Frick (2013) exemplifica que a maior fábrica de impressão em 3D no mundo, Materialise, atua há mais de 20 anos no setor, e atualmente imprime 400 mil peças/ano e emprega cerca de 900 pessoas. Dentre elas apenas 50 são operadores (impressão e acabamento), a maioria está envolvida no processo de design. Seus clientes podem acelerar o processo de impressão com upload de arquivos, através dos sites da empresa, fazer cotação instantânea e receber por entrega rápida, além de ter apoio dos funcionários em caso de dúvida nos projetos. Quando comparados com outra empresa de impressão 3D, Shapeways, que também oferece upload de arquivos, cotação instantânea, entrega e uma plataforma para os consumidores, que com menos de 100 empregados recebe $60 \mathrm{mil}$ upload/mês. A razão da diferença no número de empregados está no tipo de indústria e seu foco de mercado, pois, enquanto uma foca em produtos que normalmente precisam de orientações, na outra os produtos são mais simples e seus consumidores preferem encontrar suas próprias respostas. Assim, Frick (2013) acredita que, com o crescimento da comunidade Maker, no futuro a impressão 3D necessitará de um menor número de profissionais da área de criação.

Entre os posicionamentos contrários a Frick, expostos on-line pelos participantes da discussão, estão os que argumentam que a impressão em 3D, ou o uso do software que o alimenta, não efetuam o exercício de design. Tais tarefas ainda requerem um designer em todos os níveis das exigências do projeto. É possível que muitos gerentes comprarão softwares por acreditarem que qualquer funcionário será capaz de criar o próximo folheto ou produto da empresa, ou seja, sempre haverá aqueles que não podem discriminar entre uma ferramenta e um solucionador de problemas. Esta é, de fato, uma má interpretação sobre o que qualquer ferramenta faz, pois, a qualidade é conduzida pela pessoa por trás da ferramenta, não o oposto. Alguns apontam a importância da cooperação entre design e engenharia, sendo que algumas escolas de engenharia já estão endossando esse caminho para melhorar a 
empregabilidade. Justificam que os projetos com pouca atenção estética, produzidos pela engenharia precisam de profissionais do design e marketing para desenvolver ajustes ergonômicos, desejáveis até para se vender o produto.

Para Bass (2014) as grandes mudanças derivadas do mercado de alta tecnologia, destacando a robótica avançada, vão melhorar e inquietar nosso mundo. 0 design inteligente estará na vanguarda desta tecnologia uma vez que "pela primeira vez na história podemos distinguir designer e fabricação, pois todas as informações necessárias para a impressão do objeto estarão embutidas no design". Neste contexto a participação do designer é importante na elaboração de produtos bem sucedidos, pois o grande acesso de fabricação pelo público institui ao designer a preocupação projetual em conceber produtos funcionais, ergonômicos, sustentáveis e agradáveis.

\subsection{Interações do design com o DIY}

Favorecidas pela Terceira Revolução Industrial, pessoas estão lançando novos negócios DIY entre seus amigos para preencher lacunas não cumpridas pelas empresas tradicionais, bem como lucrar como suas redes pessoais, agora amplificadas graças à mídia social. Segundo Anderson (2012) o movimento Maker não cria hierarquia com base em credenciais. Os amadores exercem tanta influência quanto os profissionais, característica de toda comunidade de inovação aberta: quando se aceitam as contribuições de qualquer pessoa, avaliada nos próprios méritos.

Durante décadas, o design foi considerado uma província de especialistas. Mas nos últimos anos, a internet permitiu que designers amadores e pessoas habilidosas criassem, produzissem e colocassem seus projetos diretamente no mercado (SILVER, 2012). A web tem proporcionado facilidade de acesso aos materiais, fabricantes, fornecedores, dezenas de potenciais compradores e profissionais que antes exigiam relações corporativas e produção em grande escala para serem adquiridos.

Anteriormente os projetos $D / Y$ tendiam para o que é simples e direto. Ocorriam várias limitações na autoprodução, especialmente se o produto era mais complexo. Mas a paixão, dedicação e empenho dos Makers fazem com que muitos acreditem em suas ideias, simplesmente pelo fato de que pelo menos num primeiro momento estavam projetando para si mesmos. Segundo Silver (2012) isso se contrapõe às limitações naturais em pesquisas em design que precisam entender um público-alvo. Assim, não é de se espantar que quando DIYers são capacitados para projetar e construir suas próprias soluções, eles façam um bom trabalho.

O processo criativo dos DIYers pode ser instrutivo para os designers. Segundo Silver (2012):

Durante o processo de design, quantas vezes designers constroem para si mesmos e consideram se querem usar o produto? Quantas vezes canalizam paixões, curiosidades e crenças nas coisas que constroem? Sem dúvida nós temos focado no "outro" por muito tempo, imaginando o que nos torna diferente e único. Isso às vezes gera ideias inteligentes e melhores produtos. Mas também cria uma distância problemática entre os usuários e nós (designers). Isso pode impedir nosso trabalho resultando em produtos sem vida, genéricos. A boa identificação com o público alvo permite desenvolver produtos que gostamos de usar, que outros também gostam de usar e que terão maior chance de sucesso de venda para clientes, amigos ou através da internet (SILVER, 2012).

Em palestras focadas em "Fazedores Pensantes", Massimo Banzi (criador do Arduino) e Catarina Mota especialista em materiais inteligentes, enfatizaram que 
makers muitas vezes criam produtos bacanas, divertidos e rápidos, pois a maioria é produzida em horas fora do "trabalho oficial". Afirmam que paixão é essencial, e sempre foi o combustível para os novos objetos e ideias mais interessantes.

\section{CONSIDERAÇÕES FINAIS}

O estudo de artigos, livros, revistas, sites, catálogos e vídeos, iniciado com a temática do $D / Y$, revelaram a importância em se compreender também a trajetória industrial sob aspecto técnico e social, desde autores clássicos a contemporâneos. Através do estudo realizado foi possível relacionar temas pertencentes a diferentes níveis de consolidação. Partindo de um embasamento histórico amplamente publicado quanto a industrialização, aos primórdios do Do-It-Yourself e do design, foi possível caminhar para um período contemporâneo e incerto que instiga leitores, promove questionamentos, debates e comentários, principalmente por meio dos blogs e sites direcionados. O Design foi elemento chave para unir esses temas, pois sua atuação geralmente está associada ao ambiente industrial, e seus projetos atendem a aspectos de uso, percepção e adequação voltadas ao usuário.

Ao apontar, de maneira inicial, as ricas possibilidades advindas da Terceira Revolução Industrial, cabe a nós designers participarmos ativamente e estarmos à frente desses debates, amadurecendo quanto aos limites e implicações decorrentes da influência das novas técnicas em atividades projetivas, considerando a gradativa retomada de um consumidor mais participativo e consciente.

Salientamos que a Terceira Revolução Industrial com seus avanços tecnológicos é tema recente e declarações sobre suas características e amplitudes são feitas, principalmente, por autores entusiastas, sendo as críticas sobre esse tema ainda raras. Assim, a leitura desse artigo deve ser ponderada nesta questão.

Os termos popularização e acessibilidade dos equipamentos da Terceira Revolução Industrial muito empregados neste trabalho são justificados com base no caso da queda da patente de Scott Crump para a impressora 3D em 2009 e a consequente redução dos preços e popularização das formas de acessar essa tecnologia, acompanhado pelo crescimento das redes de financiamento e das startups.

É desejável que o presente trabalho possa contribuir para instigar pesquisas futuras, que tratem principalmente do contexto social e econômico brasileiro, que ainda se mostra incipiente nas questões de industrialização atrelada ao DIY.

\section{REFERÊNCIAS}

ANDERSON, Cris. Makers: A nova revolução industrial. Tradução: Crown Business. 1.ed. Rio de Janeiro: Elsevier, 2012. Título original: Makers, the new industrial revolution.

ATKINSON, Paul. Do It Yourself: Democracy and Design. Journal of Design History, recuero

CARDOSO, Rafael. Uma Introdução à Historia do Design. 3.ed. São Paulo: Blucher, 2008.

GELBER, Steven M. Do-It-Yourself: Constructing, Repairing and Maintaining Domestic Masculinity. The American Study Association, Washington, v. 49, n. 1, mar. 1997.

KOFF, William; GUSTAFSON, Paul. 3D Printing and the future of manufacturin. CSC slick Leading Edge recuero. Forum, USA, out. 2012. 
KOTLER, Philip. Administração de marketing - análise, planejamento, implementação e controle. 4 ed. São Paulo: Atlas,1994.

RECUERO, Raquel. Redes Sociais na Internet. 2 ed. Porto Alegre: Meridional, 2009.

WATSON, Matt; SHOVE, Elizabeth. Doing it yourself? Products, competence and meaning in the practices of DIY. European Sociological Association Conference, Torum, Polonia. 2005.

WIKSTRÖM, Solveig. Value Creation by Company-Consumer Interaction. Journal of Marketing Management. Stockholm, v.12. 359- p.1996.

WOKMACK, James. P.; JONES, Daniel. T.; ROSS, Daniel. A máquina que mudou o mundo. Tradução: Ivo Korytowaki. 10 ed. Rio de Janeiro: Elsevier, 2004.

WOLF, Marco; McQUITTY, Shaun. Understanding the do-it-yourself consumer: DIY motivations and outcomes. AMS Review. v 1. 154-170 p. 2011.

BASS, Carl. Schedule SXSW. [2014]. Disponível em <http://schedule.sxsw.com/2014/events/event_InickAP25552> Acesso em: 18 maio 2014

CARSON, Kevin. Homebrew Industrial Revolution. The Small Workshop, Desktop Manufacturing, and Household Production. [2010]. Disponível em:

$<$ http://blog.p2pfoundation.net/homebrew-industrial-revolution-chapter-five-thesmall-workshop-desktop-manufacturing-and-household-production-firstexcerpt/2010/12/28> Acesso em: 23 abr. 2014

FRICK, Lindsey. Machine Design. Will the 3D printing revolution kill engineering jobs?. [2013]. Disponível em: <http://machinedesign.com/editorial-comment/will-3dprinting-revolution-kill-engineering-jobs> 24 abr. 2014

LEMOS, Manoel. Blog Fazedores. [2013; 2014]. Disponível em <http://blog.fazedores.com/> Acesso em: 25 abr. 2014.

MCCUTCHEON, Robert. Limitations of 3D printing. PWC Industrial Insight Blog. [2014]. Disponível em: <http://usblogs.pwc.com/industrialinsights/?p=725> Acesso em: 13 maio 2014.

SILVER, Adam. Design Mind. What professional designers can learn from the DIY crowd. [2012]. Disponível em:

$<$ http://www.theatlantic.com/technology/archive/2012/02/what-professionaldesigners-can-learn-from-the-diy-crowd/252719/> Acesso em: 28 maio 2014

SLICK, Justin. Roadblocks and Implications for 3D Printing-The future of 3D Printing. ABOUT.com.3D. [2014]. Disponível em: <http://3d.about.com/od/3dElectronics/tp/Roadblocks-And-Implications-For-3d-Printing-The-Future-Of-3dPrinting.htm> Acesso em: 12 maio 2014. 